\title{
PENINGKATAN PENGETAHUAN PEMBIMBNG KLINIK MELALUI PELATIHAN METODE PRECEPTORSHIP DAN MENTORSHIP
}

\author{
Kurniati Puji Lestari ${ }^{*}{ }^{*}$ Muhamad Jauharb, Ike Puspitaningrumc, Shobirund, \\ Iis Sriningsih ${ }^{\mathrm{e}}$, Mugi Hartoyo ${ }^{\mathrm{f}}$ \\ a, c, d, e,f Jurusan Keperawatan; Poltekkes Kemenkes Semarang \\ Jalan Tirto Agung Pedalangan Banyumanik Semarang \\ ${ }^{b}$ Jurusan Keperawatan, Fakultas Ilmu Kesehatan, Universitas Muhammadiyah Kudus \\ Jalan Ganesha 1 Purwosari Kudus
}

\begin{abstract}
Abstrak
Preceptors bertugas mengajar, menasihati, menginspirasi, panutan, serta mendukung tumbuh kembang mahasiswa keperawatan. Model bimbingan preceptroship adalah proses pendelegasian wewenang dari pembimbing kepada mahasiswa. Metode Pelatihan Preceptorship memfasilitasi pembelajaran tentang pengetahuan, keterampilan, dan perilaku preceptor. Tujuan kegiatan pengabdian kepada masyarakat ini adalah untuk memberikan bekal bimbingan klinis dalam menerapkan pembelajaran klinik aktif. Metode kegiatan melalui pelatihan Preceptorship, dengan pre dan post test, ceramah, simulasi peran, evaluasi, dan pendampingan bimbingan klinis. Preceptor adalah $56,5 \%$ perempuan, dan $52,2 \%$ memiliki pengalaman pelatihan bimbingan klinis. Rerata pengetahuan sebelum pelatihan 27,74 dengan SD 12,638, dan rerata 52,74 dan SD 20,324 setelah pelatihan. Ada perbedaan yang signifikan antara pengetahuan sebelum dan sesudah pelatihan dengan p-value $=0,000(p<0,05)$. $31 \mathrm{CI}(77,5 \%)$ menyatakan tema pelatihan sangat baik, $23 \mathrm{CI}(57,5 \%)$ menyatakan ketepatan waktu sangat baik, 23 CI (53,5\%) menyatakan bahwa layanan penyelenggara sangat baik. Pelatihan Metode Pembelajaran Preceptorship meningkatkan pengetahuan pembimbing klinik. Kegiatan ini dapat diintegrasikan dalam perencanaan pembelajaran klinik kerjasama antara pihak pendidikan dan pelayanan.
\end{abstract}

Kata kunci: pelatihan, pengetahuan, pembimbing klinik, preceptorship, mentorship

\begin{abstract}
[CLINICAL INSTRUCTOR'S KNOWLEDGE IMPROVEMENT THROUGH PRECEPTORSHIP AND MENTORSHIP METHOD TRAINING] Preceptors are tasked with teaching, advising, inspiring, role models, and supporting the growth and development of nursing students. Preceptroship guidance model is the process of delegating authority from supervisors to students. Preceptorship Training Methods facilitate learning about preceptor knowledge, skills and behaviors. The activity method is through Preceptorship training, with pre and post tests, lectures, role simulations, evaluation, and clinical guidance assistance. The preceptor was $56.5 \%$ female, and $52.2 \%$ had clinical guidance training experience. The mean of knowledge before training was 27.74 with SD 12.638, and the mean was 52.74 and SD 20.324 after training. There is a significant difference between the knowledge before and after training with p-value $=0.000(\mathrm{p}<0.05) .31 \mathrm{CI}(77.5 \%)$ stated that the training theme was very good, $23 \mathrm{CI}(57.5 \%)$ stated that the timeliness was very good, $23 \mathrm{CI}(53.5 \%)$ stated that the service provider was very good. Preceptorship Learning Methods training enhances the clinical supervisor's knowledge. This activity can be integrated in the planning of clinical learning in collaboration between education and service authorities
\end{abstract}

Keywords: clinical instructor; knowledge; mentorship; preceptorship; training

\section{Pendahuluan}

Perkembangan keperawatan sebagai profesi saat ini dan masa yang akan datang dihadapkan pada berbagai tantangan yaitu

*) Correspondence Author (Kurniati Puji Lestari) E-mail: kurniati_pujilestari@yahoo.com berkembangnya ilmu pengetahuan dan teknologi kesehatan, tuntutan masyarakat akan layanan yang berkualitas, pengembangan profesi keperawatan, meningkatnya kompleksitas penyakit, respon pasien terhadap penyakit, pengobatan dan lingkungan. 
Pendidikan dan keilmuan keperawatan perlu diarahkan untuk menghasilkan perawat yang memiliki pengetahuan dan keterampilan dalam melakukan asuhan keperawatan pada klien baik secara individu, keluarga, kelompok, dan masyarakat (Lestari et al., 2019). Menurut (Kurniawan \& Bahtiar, 2018) Pembelajaran klinik sangat penting dilakukan dalam tahapan pendidikan profesi sehingga lulusan mampu memberikan pelayanan yang berkualitas pada masyarakat. Kemampuan memberikan pelayanan dapat dipelajari melalui praktik laboratorium sehingga mahasiswa mendapatkan gambaran yang nyata dalam melakukan pembelajaran di klinik.

Pembimbing klinik memiliki wewenang dan tanggung jawab dalam merencanakan, mengelola, melaksanakan dan mengevaluasi pembelajaran klinik. Fenomena yang ditemukan di lahan praktik, beberapa pembimbing klinik belum menunjukkan kemampuannya dalam membimbing praktikan karena kurangnya kepercayaan diri dan ketidakjelasan peranan yang diberikan institusi pendidikan pada pembimbing klinik tersebut (Suprati, 2019). Tahap pendidikan profesi Ners merupakan proses adaptasi praktikan untuk dapat menerima pendelegasian kewenangan secara bertahap dalam melakukan asuhan keperawatan profesional, memberikan pendidikan kesehatan, menjalankan fungsi advokasi, membuat keputusan legal dan etik, dan menggunakan hasil pengabdian kepada masyarakat terkini yang berkaitan dengan keperawatan (Asosiasi Institusi Pendidikan Ners Indonesia \& (AIPNI), 2016). Dalam mendukung hal tersebut, perlu adanya program pelatihan yang diberikan kepada pembimbing klinik dalam meningkatkan kapasitas bimbingan klinik.

Pelatihan merupakan suatu proses sistematis untuk meningkatkan kompetensi, mengubah perilaku dalam mendukung untuk mencapai tujuan organisasi yang berhubungan dengan pengembangan kompetensi, disiplin, produktifitas dan etos kerja (Suprati, 2019). Pelatihan Preceptorship di Rumah Sakit perlu dilakukan untuk refreshing dan evaluasi pelaksanaannya, karena masih terdapat kesenjangan antara kemampuan Perseptor dalam implementasi metode bimbingan, rasio perbandingan perseptor dengan perseptee, syarat perseptor serta peningkatan kualitas dan kompetensi perseptor (Kurniawan \& Bahtiar, 2018).
Preseptor adalah seseorang yang telah memiliki pengalaman pada pelayanan kesehatan, bekerja bersama praktikan pada tatanan klinik, berperan sebagai pendidik klinis sekaligus sebagai seorang perawat profesional. Preseptor bertugas untuk membimbing mahasiswa keperawatan atau perawat baru untuk belajar menerapkan teori dan pengetahuan yang dimiliki (Renu et al., 2015). Preseptor keperawatan merupakan kunci proses pelaksanaan pembelajaran klinis. Preseptor harus dapat menjadi teladan dalam pelaksanaan asuhan keperawatan dengan pendekatan evidence base practice (Koy, 2015). Seorang preseptor diharapkan mampu mendemonstrasikan keterampilan, memberikan solusi, berpikir kritis, berdasarkan kondisi klinis, dan memiliki keterampilan memgambil keputusan pada area praktik (Marcia Gardner, 2010)

Kathleen B. Gaberson; Marilyn H. Oermann mendeskripsikan 4 domain kompetensi yang harus dimiliki seorang preseptor yaitu: pengetahuan preseptor harus memiliki pengetahuan yang memadai tentang pasien (tipe, permasalahan, dan pengelolaan), teknologi baru dan riset-riset yang berhubungan dengan pengelolaan pasien. Domain kompetensi preseptor yang kedua adalah kompetensi klinis preseptor akan mampu membimbing mahasiwa jika memiliki kompetensi klinis yang baik. Domain komptensi ketiga yaitu kemampuan mengajar di klinis preseptor harus tahu bagaimana cara mengajar. Domain kompetensi keempat hubungan interpersonal dengan mahasiswa kemampuan pendidik klinis untuk berinteraksi dengan mahasiswa (Kathleen B. Gaberson; Marilyn H. Oermann, 2010). Tujuan kegiatan pengabdian kepada masyarakat ini yaitu mengidentifikasi perbedaan pengetahuan pembimbing klinik tentang metode preceptorship dan mentorship sebelum dan setelah diberikan pelatihan preceptorship dan mentorship di rumah sakit pendidikan.

\section{Metode}

Kerangka berfikir dalam kegiatan pengabdian kepada masyarakat ini terdiri dari input, proses dan output. Input adalah kegiatan pembelajaran klinik pendidikan profesi ners. Prosesnya berupa pelatihan metode preceptorship dan mentorship. Output yaitu peningkatan pengetahuan pembimbing klinik tentang metode preceptorship dalam 
pembelajaran klinik. Kegiatan pelatihan dilakukan pada 5-6 September 2019 di RSUP Dr. Kariadi dengan jumlah pembimbing klinik sebanyak 46 orang. Materi yang diberikan terdiri dari kebijakan rumah sakit dalam pembelajaran klinik, kerjasama institusi pendidikan dan pelayanan dalam dalam proses pembelajaran klinik, konsep preseptorship dan mentorship, aspek legal etik bimbingan klinik, pengembangan program pembelajaran klinik, metode penilaian klinik, dan praktik berbasis bukti dalam keperawatan.

Jumlah waktu materi sebanyak 25 JPL terdiri dari 14 JPL teori, 9 JPL praktika, dan 2 JPL praktik lapangan. Pelatihan ini diawali dengan pre-test dan diakhiri dengan post-test. Instrumen yang digunakan yaitu kuesioner pengetahuan tentang preceptorship dan mentorship sebanyak 30 soal pilihan ganda yang dikembangkan oleh penulis. Metode pelatihan berupa ceramah, diskusi tanya jawab, simulasi, dan roleplay. Pembimbing klinik diberikan modul pelatihan yang telah tercatat di Surat Pencatatan Ciptaan dari Kementerian Hukum dan Hak Asasi Manusia tentang Hak Kekayaan Intelektual (HKI) nomor EC00201979503 tanggal 1 November 2019 dan nomor ISBN 978-602-6536-66-2 dari Perpustakaan Nasional Republik Indonesia. Pembimbing klinik mengisi lembar evaluasi kegiatan pelatihan dan narasumber setelah mengikuti pelatihan.

\section{Hasil dan Pembahasan}

Tabel 1 mendeskripsikan karakteristik pembimbing klinik RSUP Dr. Kariadi terdiri dari jenis kelamin dan pengalaman pelatihan pembimbing klinik.

Tabel 1 Distribusi frekuensi karakteristik pembimbing klinik RSUP Dr. Kariadi

\begin{tabular}{lcc}
\hline \multicolumn{1}{c}{ Variabel } & f & \% \\
\hline Jenis kelamin & & \\
Laki-laki & 20 & 43,5 \\
Perempuan & 26 & 56,5 \\
\hline Pengalaman mengikuti pelatihan & & \\
pembimbing klinik & & \\
Pernah & 22 & 47,8 \\
Tidak Pernah & 24 & 52,2 \\
\hline Total & 46 & 100 \\
\hline
\end{tabular}

Tabel 1 menunjukkan sebagian besar pembimbing klinik RSUP Dr. Kariadi adalah perempuan yaitu sebanyak 26 orang $(56,5 \%)$ dan sebagian besar pembimbing klinik atau sebanyak 24 orang $(52,2 \%)$ tidak memiliki pengalaman mengikuti pelatihan pembimbing klinik.

Tabel 2 mendeskripsikan pengetahuan pembimbing klinik tentang preceptorship dan mentorship sebelum dan sesudah diberikan pelatihan. Didapatkan rerata pengetahuan pembimbing klinik sebelum pelatihan sebesar 27,74 dengan SD 12,64 dan 95\% CI 23,11-32,38. Rerata pengetahuan pembimbing kliniksesudah pelatihan sebesar 52,74 dengan SD 20,32 dan 95\% CI 45,29-60,20.

Tabel 2. Gambaran pengetahuan pembimbing klinik RSUP Dr. Kariadi sebelum dan sesudah pelatihan

\begin{tabular}{cccc}
\hline Pengetahuan & Mean & SD & $\mathbf{9 5 \% ~ C I ~}$ \\
\hline Sebelum & 27,74 & 12,64 & $23,11-32,38$ \\
\hline Sesudah & 52,74 & 20,32 & $45,29-60,20$ \\
\hline
\end{tabular}

Tabel 3 menjelaskan tentang perbedaan pengetahuan pembimbing klinik tentang preceptorship dan mentorship sebelum dan sesudah pelatihan. Terdapat perbedaan yang signifikan pengetahuan pembimbing klinik tentang preceptorship dan mentorship sebelum dan sesudah pelatihan dengan nilai $p<0,001$ (nilai $\mathrm{p}<0,05)$ dan perbedaan reraata sebelum dan setelah pelatihan sebesar 25,00.

Tabel 3. Perbedaan pengetahuan pembimbing klinik RSUP Dr. Kariadi sebelum dan sesudah pelatihan

\begin{tabular}{ccccc}
\hline Pengetahuan & Mean & SD & MD & Nilai p \\
\cline { 1 - 3 } Sebelum & 27,74 & 12,638 & & $<$ \\
\cline { 1 - 3 } Sesudah & 52,74 & 20,324 & & $<00$ \\
\hline
\end{tabular}

Tabel 4. Menggambarkan tentang evaluasi kegiatan pelatihan metode preceptorship dan mentorship dari pembimbing klinik RSUP Dr. Kariadi. Sebanyak 40 pembimbing klinik dari 46 pembimbing klinik yang mengisi lembar evaluasi secara lengkap. Hasil penelitian menyebutkan bahwa sebagian besar pembimbing klinik atau sebanyak 31 orang $(77,5 \%)$ menyatakan tema pelatihan baik, setengahnya pembimbing klinik atau sebanyak 23 orang $(57,5 \%)$ menyatakan ketepatan waktu baik, sebagian besar pembimbing klinik atau sebanyak 31 orang $(77,5 \%)$, menyatakan suasana pelatihan baik, sebagian besar pembimbing klinik atau sebanyak 26 orang (65\%) menyatakan kelengkapan materi baik, 
setengahnya pembimbing klinik atau sebanyak 23 orang $(53,5 \%)$ menyatakan pelayanan penyelenggara baik, dan sebagian besar pembimbing klinik atau sebanyak 25 orang $(62,5 \%)$.

Tabel 4 Evaluasi kegiatan pelatihan metode preceptorship dan mentorship di RSUP Dr. Kariadi

\begin{tabular}{lcc}
\hline \multicolumn{1}{c}{ Aspek Penilaian } & f & \% \\
\hline Tema pelatihan & 31 & 77,5 \\
Baik & 9 & 22,5 \\
Memuaskan & & \\
\hline Ketepatan waktu & 5 \\
Kurang & 7 & 17,5 \\
Cukup & 23 & 57,5 \\
Baik & 8 & 20 \\
Memuaskan & & \\
Suasana pelatihan & 4 & 5,6 \\
Cukup & 31 & 43,7 \\
Baik & 5 & 12,5 \\
Memuaskan & & \\
\hline Kelengkapan materi & 4 & 5,6 \\
Cukup & 26 & 36,6 \\
Baik & 10 & 14,1 \\
Memuaskan & & \\
\hline Pelayanan penyelenggara & 2 & 2,8 \\
Cukup & 23 & 32,4 \\
Baik & 15 & 21,1 \\
Memuaskan & & \\
\hline Media yang digunakan & 4 & 5,6 \\
Cukup & 25 & 35,2 \\
Baik & 11 & 15,5 \\
\hline Memuaskan & $\mathbf{4 0}$ & $\mathbf{1 0 0}$ \\
\hline \multicolumn{1}{c}{ Total } & & \\
\hline
\end{tabular}

Grafik 1. Menunjukkan hasil evaluasi narasumber pelatihan preceptorship dan mentorship dari pembimbing klinik RSUP Dr. Karidi. Sebanyak 40 pembimbing klinik dari 46 pembimbing klinik yang mengisi lembar kuesioner secara lengkap.

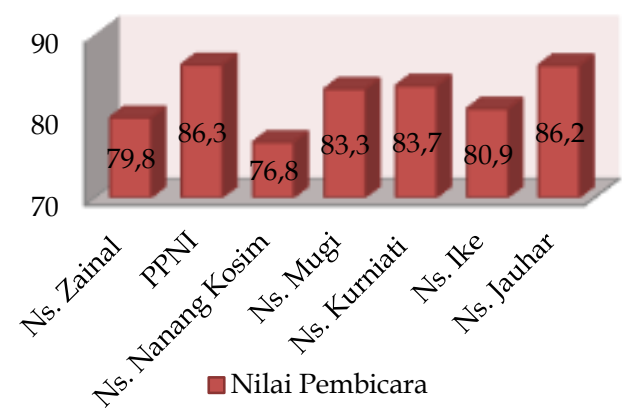

Grafik 1. Evaluasi narasumber pelatihan preceptorship dan mentorship di RSUP Dr. Kariadi
Hasil perhitungan statistik menunjukkan jumlah nilai narasumber per sesi materi dengan rentang nilai 0-100 terdiri dari Ns. Zainal Arifin sebesar 79,8; PPNI sebesar 86,3; Ns. Nanang Kosim sebesar 76,8; Ns. Mugi Hartoyo sebesar 83,3; Ns. Kurniati Puji Lestari sebesar 83,7; Ns. Ike Puspitaningrum sebesar 80,9; dan Ns. Muhamad Jauhar sebesar 86,2.

Pendidikan Profesi Keperawatan tidak terlepas dari Pembelajaran klinik dengan metode Pembelajaran Preceptorship karena akan mempunyai pengaruh yang sangat kuat terhadap kompetensi mahasiswa profesi Ners sebagai calon perawat, yang akan mempengaruhi juga pelayanan keperawatan yang diberikan kepada pasien saat bekerja di pelayanan kesehatan (Yeni Rusyani, 2019) Pelatihan merupakan pengalaman belajar yang dirancang untuk membantu peserta latih menguasai kompetensi yang tidak dimiliki sebelumnya. Program pelatihan diharapkan sebagai upaya untuk mencapai kompetensi pengetahuan, ketrampilan dan sikap yang segera dapat digunakan untuk meningkatkan kinerja. Pencapaian kompetensi dalam pembelajaran Berdasarkan (Vecchia \& Sparacino, 2015) perempuan lebih matang terutama kognitifnya sehingga mereka memiliki ingatan, pengolahan Bahasa dan psikomotor halus yang lebih baik dibandingkan laki-laki. Menurut (Yeni Rusyani, 2019) dalam berinteraksi antara lakilaki dan perempuan mempunyai karakter yang berbeda, perhatian dan cara berkomunikasi. Perempuan lebih supel atau pandai menyesuaikan diri saat berinteraksi dengan orang lain.

Menurut (Benny A. Pribadi, 2016) Pelatihan merupakan pengalaman belajar yang sengaja dirancang agar dapat membantu peserta dalam menguasai kompetensi yang tidak dimiliki sebelumnya. Program pelatihan dapat di maknai sebagai pengalaman pembelajaran yang menfokuskan pada upaya individu untuk memperoleh ketrampilan spesifik yang dapat segera digunakan. Dari peserta latih sebanyak (52,2\%) memiliki pengalaman mengikuti pelatihan pembimbing klinik, sesuai dengan hasil pelatihan signifikan mengalami peningkatan pengetahuan di akhir evaluasi pelatihan. Pendidikan dan pelatihan merupakan alat untuk menyesuaikan antara tugas dan pekerjaan dengan kemampuan, ketrampilan atau kecakapan dan keahlihan dari setiap karyawan serta merupakan usaha untuk meningkatkan kinerja karyawan sebagai proses 
adaptasi pekerjaan tertentu. Tujuan mengikuti pelatihan agar dapat mengingatkan kembali tugas-tugas dan tanggung jawab dalam meningkatkan pencapaian tingkat moral kerja yang lebih tinggi (Mamik Eko Supatmi, 2016). Sejalan dengan pendapat Andrew (2009) dalam (Mamik Eko Supatmi, 2016) bahwa pelatihan adalah proses pendidikan jangka pendek yang mempergunakan prosedur sistematis dan terorganisasi, pegawai non manajerial mempelajari pengetahuan dan ketrampilan teknis dalam tujuan yang terbatas.

Menurut (Suprati, 2019) pelaksanaan model pelatihan bahwa proses dalam memfasilitasi pembelajaran yang berkaitan dengan pengetahuan, keahlihan dan perilaku karyawan. Ada beberapa factor yang mempengaruhi keberhasilan proses belajar untuk meningkatkan pengetahuan Pembimbing klinik dalam pelatihan terbagi menjadi dua factor, yaitu factor internal dan factor eksternal. Factor internal yang mempengaruhi proses belajar dalam pelatihan adalah perhatian, minat dan bakat (Slameto, 2013). Factor-faktor eksternal yang turut mempengaruhi peningkatan pengetahuan pembimbing klinik tentang metode Preceptorship adalah kurikulum, metode mengajar, alat bantu belajar, relasi naras umber dengan peserta pelatihan dalam proses belajar. Menurut Herawati (2000) dalam (Lestari et al., 2019) bahwa instruktur klinik harus mampu menjadi pengawas, memastikan kesiapan mahasiswa dalam melakukan tindakan, berbagai ilmu, memastikan mahasiswa mencapai standar kompetensi yang telah ditetapkan.

Pelatihan Preceptorship sebagai upaya yang dilakukan untuk meningkatkan kemampuan dalam kinerja sesuai dengan tujuan institusi mencakup pengembangan ketrampilan agar kompetensi dilakukan secara cepat dan efektif, pengetahuan menggunakan pendekatan berfikir kritis berdasar evidence based dan mengambangkan sikap sehingga tercipa kerja sama yang baik dengan tim dan mahasiswa praktikan. Pelatihan Preceptorship memberikan kesempatan kepada peserta latih untuk memperoleh penyegaran metode pembelajaran dengan pendekatan perencanaan bimbingan yang diawali dengan pre conference bersama perceptee berdiskusi tentang rencana asuhan keperawatan menggunakan pendekatan Evidance Based Practice. Pendampingan bimbingan menggunakan strategi pembelajaran yang komprehensif dengan di akhiri diskusi pada saat Post Conference, sehingga dapat menemukan kendala yang dihadapi, cara pemecahan masalah yang dijumpai yang bermanfaat agar mahasiswa mampu berfikir kritis (Lestari et al., 2019).

Pelatihan Preceptorship sebagai proses aktifitas dalam memberikan kesempatan peserta latih mengikuti pembelajaran untuk mendapatkan kompetensi yang terstruktur sebagai Preceptor melalui beberapa strategi pembelajaran ceramah interaktif, diskusi kelompok, bermain peran, demonstrasi dan evaluasi. Kemampuan peserta latih diukur dari hasil pre test dibandingkan dengan post test terdapat perbadaan yang signifikan, peningkatan pengetahuan peserta latih sangat bermakna. Menurut (Omer et al., 2013), pelatihan model preceptorship membawa dampak pengalaman yang positif, meningkatkan ketrampilan, dapat membantu proses transisi kemampuan, mempercepat proses adaptasi dan peserta latih dapat melakukan peran sebagai preceptee dalam tiga tahap meliputi persiapan, pelaksanaan dan evaluasi. Proses pembelajaran yang dilakukan dengan praktik langsung dan melakukan hal yang nyata, mempunyai kecenderungan masih mengingat 90\% materi yang diajarkan, karena peserta pelatihan bersifat aktif. Karena model pelatihan Preceptorship karena merupakan model pelatihan yang menekankan pada praktik langsung dengan pendampingan dan bimbingan Preceptor. Dengan melakukan praktik langsung dan terus menerus diharapkan peserta latih akan lebih meningkat kompetensinya. Hasil penelitian (Suprati, 2019) model bimbingan preceptorship pada praktik klinik di Rumah Sakit mampu meningkatkan kompetensi pada mahasiswa.

Pelatihan menjadi penting dalam mengembangkan sumber daya manusia yang membutuhkan manajemen yang baik. Manajemen pelatihan Preceptorship adalah kegiatan pelatihan yang mendayagunakan sumber daya manusia, sarana dan prasarana serta berbagai potensi yang tersedia atau yang dapat disediakan untuk digunakan secara efisien dan efektif dalam mencapai tujuan metode pembeljaran preceptorship. Pelatihan Preceptorship diselenggarakan dengan pemberian materi sesuai standar yang ditetapkan oleh PPNI sebagai organisasi profesi yang mengeluarkan ijin pelatihan dan sertifikat dengan Satuan Kredit Profesi (SKP). Banyak komponen yang dinilai dari jalannya pelatihan 
meliputi metode pelatihan, materi pelatihan, suasana pelatihan, sarana prasarana, jadwal pelatihan, fasilitator dan naras umber pelatihan. Setiap pemateri memiliki gaya khas sendiri dalam menyampaikan materi dan setiap materi harus benar-benar di terima oleh peserta latih (Suprati, 2019). Dari hasil evaluasi penyelenggaraan pelatihan, hampir sebagian besar pemateri mendapat nilai Baik dan sangat baik dalam penyampaian materi dari peserta latih. Menurut evaluasi peserta latih dari ketepatan waktu dalam kegiatan pelatihan, suasana pelatihan mendapat nilai baik dan memuaskan hampir diatas $70 \%$. Sedangkan pelayanan penyelenggaraan pelatihan dan media yang digunakan hampir $85 \%$ peserta latih memberikan nilai baik dan memuaskan.

Melalui pelatihan Preceptorship dapat mewujudkan Pelayanan Keperawatan yang berkualitas dengan memperhatikan perkembangan keilmuan, budaya dan teknologi. Pembentukan kamampuan tersebut diperlukan tahapan proses pembentukan karakter Preceptor yang profesional melalui pelatihan, peningkatan pendidikan yang berkelanjutan dalam membentuk kemampuan intelektual, teknikal dan interpersonal, bekerja berdasarkan standar praktik, memperhatikan kaidah etik dan moral. Preceptor diharapkan mampu meningkatkan self confidence mahasiswa Profesi Ners menggunakan Evidence Based Practice dalam melakukan interpretasi, analisa, explanation dan inferesial dalam mencari informasi yang mendukung argumentasi ilmiah yang merupakan komponen penting Critical thinking. Preceptorship merupakan metode pembelajaran klinik yang memiliki potensi memfasilitasi mahasiswa mendorong refleksi dan meningkatkan kemampuan berpikir kritis (Sulung, 2016).

\section{Simpulan dan Saran}

Pelatihan metode preceptorship dan mentorship dapat meningkatkan pengetahuan pembimbing klinik tentang pembelajaran klinik. Pengetahuan yang baik berkontribusi dalam peningkatan kapasitas pembimbing klinik dalam melakukan bimbingan klinik terhadap praktikan di lahan praktik. Tercapainya kompetensi mahasiswa keperawatan dalam proses pembalajaran klinik baik softskill maupun hardskill didukung oleh pembimbing klinik yang terlatih. Pelatihan pembimbing klinik menjadi tanggung jawab institusi pendidikan tinggi keperawatan. Hal terpenting adalah implementasi metode pembelajaran klinik preceptorship dan mentorship pasca pelatihan dengan monitoring dan evaluasi rutin dari badan koordinasi pendidikan di rumah sakit. Pembimbing klinik harus mampu menunjukkan performa yang baik selama melakukan bimbingan klinik kepada mahasiswa keperawatan. Secara rutin, institusi pendidikan memberikan penyegaran bagi pembimbing klinik tentang metode pembelajaran klinik terkini yang mampu meningkatkan kemampuan mahasiswa dalam mencapai kompetensi yang telah ditentukan. Hasil penulisan ini dapat digunakan sebagai data dasar dan pertimbangan dalam mengembangkan kegiatan dan survei lanjutan, misalnya evaluasi metode Preceptorship dan Mentorship dalam meningkatkan aspek soft skill (Komunikasi, kerjasama, caring, etik) mahasiswa atau mengembangkan intervensi lain yang dapat meningkatkan kemampuan mahasiswa keperawatan dalam mencapai target kompetensi baik softskill dan hardskill.

\section{Ucapan Terima Kasih}

Penulis mengucapkan terima kasih kepada Poltekkes Kemenkes Semarang yang telah memberikan dana hibah pengabdian kepada msyarakat, RSUP Dr. Kariadi, salah satu lahan praktik mahasiswa keperawatan, yang telah memberikan kepercayaan untuk memberikan pelatihan pembimbing klinik, dan pembimbing klinik yang telah mengikuti pelatihan dan memberikan bimbingan klinik kepada mahasiswa keperawatan.

\section{Daftar Pustaka}

Asosiasi Institusi Pendidikan Ners Indonesia, \& (AIPNI). (2016). Kurikulum Inti Pendidikan Ners Indonesia 2015 Asosiasi Institusi Pendidikan Ners Indonesia. www.aipniainec.com

Benny A. Pribadi. (2016). Desain dan Pengembangan Program Pelatihan Berbasis Kompetensi Implementasi Model ADDIE (Pertama). Prenada Media Group.

Kathleen B. Gaberson; Marilyn H. Oermann. (2010). Clinical Teaching Strategies in Nursing. In Library of Congress Calatogingin-Publication Data (Third Edit, Vol. 53, Issue 9). Spinger Publishing Company.

Koy, V. (2015). Perceptions of nursing students on effective clinical preceptors in Phnom 
Penh National Hospitals, Cambodia. International Journal of Research in Medical Sciences, 3(7), 1605-1610. https://doi.org/10.18203/23206012.ijrms20150237

Kurniawan, M. H., \& Bahtiar, B. (2018). Nurse Preceptor Experience in Preceptorship Program: A Systematic Literature Review of Qualitative Studies. International Journal of Nursing and Health Services (IJNHS), 1(1), 35-48. https://doi.org/10.35654/ijnhs.v1i1.8

Lestari, K. P., Siswanto, J., Sriningsih, I., \& Setyowati, S. E. (2019). Pelatihan Instruktur Klinik: Metode Perseptor Dalam Pembelajaran Klinik Di Lingkungan Dinas Kesehatan Kota Semarang. Link, 15(1), 7. https://doi.org/10.31983/link.v15i1.392 3

Mamik Eko Supatmi. (2016). Pengaruh Pelatihan, Kompensasi Terhadap Kepuasan Kerja Pegawai Dan Kinerja Pegawai. Jurnal Profit, 7(1), 25-37.

Marcia Gardner, P. D. S. (2010). Handbook of Clinical Teaching in Nursing and Health Sciences. Jones \& Bartlett Publishers.

Omer, T. Y., Suliman, W. A., Thomas, L., \& Joseph, J. (2013). Perception of nursing students to two models of preceptorship in clinical training. Nurse Education in Practice, 13(3), 155-160. https://doi.org/10.1016/j.nepr.2013.02. 003
Renu, M., Boonchom, S. ard, \& Apinya, J. (2015). Strengthening preceptors competency in Thai clinical nursing. Educational Research and Reviews, 10(20), 2653-2660. https://doi.org/10.5897/err2015.2468

Slameto. (2013). Belajar dan factor-faktor yang mempengaruhi. Rineka Cipta.

Sulung, N. (2016). Efektifitas Metode Preseptor dan Mentor dalam Meningkatkan Kompetensi Perawat Klinik. Jurnal IPTEKS Terapan, 9(3). https://doi.org/10.22216/jit.2015.v9i3.4 16

Suprati, S. (2019). Analisis Dampak Model Pelatihan Klasikal dan Preseptorsip terhadap Kompetensi. Jurnal Ilmiah Administrasi Publik ( JIAP ), 5(2), 196-206.

Vecchia, E. Della, \& Sparacino, L. (2015). High fidelity simulator experience for enhancing communication effectiveness: Applications to quality and safety education for nurses. Journal of Nursing Education and Practice, 5(9). https://doi.org/10.5430/jnep.v5n9p78

Yeni Rusyani. (2019). Pengaruh Pelatihan Quality and Safety Education for Nurses (QSEN) terhadap Kompetensi Patient Centered Care Preceptor di RSUP Dr. Soeradji Tirtonegoro Klaten. Jurnal Ilmu Kesehatan STIKes Duta Gama Klaten, 10(2), 93-106.

https://doi.org/https://dx.doi.org/10. 5737/e-journal.v10i2.450 